PRESENTACIÓN

\title{
Educação jurídica brasileira em tempos de pandemia
}

\author{
Renato Duro Dias \\ Director
}

Desde o seu surgimento, na cidade chinesa de Wuhan, até sua propagação em vários países, o novo coronavírus (Covid-19) tem deixado um rastro de mortes e de infecções numa escala jamais vista, quando se trata de se referir a pandemias em esfera global. Aproximadamente nove milhões de pessoas infectadas e milhares de mortes, em mais de duzentos países. A Organização Mundial da Saúde (OMS) tem expressado sua preocupação com a ampliação da força de contágio do vírus nas cidades que são marcadas pelos seus altos índices de desigualdade social e, consequentemente, precário acesso ao saneamento básico local, como são a maioria das cidades latino-americanas.

No Brasil, em que os índices de desigualdade são alarmantes, a Covid-19 pode precarizar ainda mais milhares de vidas que não possuem nenhuma espécie de proteção do Estado. Neste sentido, corre-se o risco de termos um cenário explícito de ampliação das desigualdades sociais, regionais e econômicas. Especialmente a condição humana, baseada em algumas características como a raça, as identidades de gêneros e as sexualidades vivenciadas e experimentadas pelos sujeitos, estão sujeitas ao aprofundamento das iniquidades, discriminações, abjeções e não-reconhecimentos de direitos (Dias y Brum, 2017).

É possível afirmar que a Covid-19 será um marco para a história recente na jovem democracia brasileira. Mesmo depois de um processo de esgaçamento democrático, tomando como pano de fundo o impedimento de uma Presidenta, prisão de um expresidente e um tumultuado processo eleitoral em 2018, a Covid-19 não passará sem deixar marcas profundas na memória historiográfica de nosso país. Os dados mesmo em uma situação de razoável isolamento social são alarmantes, principalmente se confrontados com estudos epidemiológicos sobre o avanço da curva no Brasil. De acordo com o último boletim divulgado pelo Ministério da Saúde, o país conta com mais de um milhão e cem mil casos notificados, e soma, aproximadamente, cinquenta e uma mil mortes. Esses tristes números geram efeitos em diversos níveis, inclusive na educação superior. 
Neste contexto, por força de Portaria do governo federal, o campo da educação jurídica tem sido instado a ocupar o espaço da virtualidade, transladando as aulas tradicionais do formato presencial para modalidades remotas. Quando se trata de um país com tantos desequilíbrios sociais e dificuldades territoriais de acesso à internet, os espaços de aprendizagem se tornam ainda mais desafiadores. Percebe-se um esforço potente entre docentes, instituições públicas de ensino superior, estudantes de direito e famílias para que este período emergencial seja experenciado positivamente como um cenário de novas ambientações e aprendizagens. No entanto, o Ministério da Educação brasileiro, até o presente momento, não apresentou nenhuma proposta ou ação que mitigue as imensas dificuldades que se vislumbram em um período de profundas urgências e emergências.

Assim, a educação jurídica superior, especialmente a produzida nas universidades públicas federais, tem pela frente um importante compromisso: produzir formação jurídica para a defesa e consolidação da democracia brasileira, com vistas à eliminação das desigualdades e ampliação de acesso à justiça.

\section{Referencias}

Dias, Renato Duro y Amanda Netto Brum (2017). «Resignificando o discurso dos direitos humanos: um dialogo a partir da educacao em e para os direitos humanos.» Quaestio Iuris, 10(4): 239-241. 
La Revista Pedagogía Universitaria y Didáctica del Derecho (RPUDD) es una publicación científica semestral que contribuye a la reflexión multidisciplinaria sobre pedagogía universitaria y didáctica del derecho, para la formación y consolidación de esta área de investigación; así como a la difusión de prácticas innovadoras en la enseñanza-aprendizaje del derecho considerando el contexto nacional e internacional. Es una publicación electrónica internacional con una codirección entre Brasil y Chile.

\author{
DIRECTORA \\ María Francisca Elgueta Rosas \\ Universidad de Chile \\ DIRECTOR \\ Renato Duro Dias \\ Universidad Federal de Rio Grande, Brasil \\ SITIO WEB \\ pedagogiaderecho.uchile.cl \\ CORREO ELECTRÓNICO \\ rpedagogia@derecho.uchile.cl \\ LICENCIA DE ESTE ARTÍ́CULO
}

Creative Commons Atribución Compartir Igual 4.0 Internacional

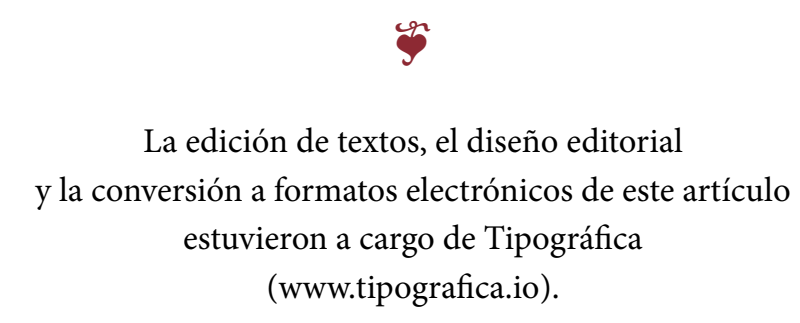

